\title{
Early to Middle Jurassic redox evolution across the Norwegian Continental Shelf: a case study in the Viking Corridor, North Sea Basin
}

\author{
KIARA JEANNELLE GOMEZ ${ }^{1}$, SWAPAN SAHOO ${ }^{2}$, \\ ELENI PANTELI ${ }^{2}$, LORENA MOSCARDELLI ${ }^{2}$, AARON \\ HOWIE $^{2}$, TOTI E LARSON ${ }^{3}$ AND CHARLES KERANS $^{1}$ \\ ${ }^{1}$ University of Texas at Austin \\ ${ }^{2}$ Equinor ASA \\ ${ }^{3}$ The University of Texas at Austin \\ Presenting Author: kiaragomez@utexas.edu
}

We present new carbon isotope $\left(\delta^{13} \mathrm{C}\right)$, redox-sensitive trace metal (RSTM), and $\mathrm{Hg}$ records from the Viking CorridorNorwegian Continental Shelf (NCS) - to assess the spatial and temporal evolution of redox conditions between Early-Middle Jurassic (186-169 Ma). We assess a global and a regional event - the Toarcian Oceanic Anoxic Event (T-OAE) and the localized uplift of the North Sea Dome (NSD; 182-170 Ma), respectively. The T-OAE is characterized by a global warming event and a perturbation of the carbon cycle - expressed as a negative $\delta^{13} \mathrm{C}$ shift-linked to $\mathrm{CO}_{2}$ release from the Karoo-Ferrar LIP (KF-LIP). The NSD acted as a large bathymetric barrier, disrupting regional paleocurrents and basin architecture.

Despite extensive studies of the T-OAE, its expression across the NCS is still limited. Similarly, while we understand the role that the NSD played in the tectonostratigraphic configuration of the NCS, the impact on redox conditions during its onset and evolution remains elusive. The scarcity of continuous EarlyMiddle Jurassic geochemical records has contributed to this gap - the focus of this study.

Results confirm the T-OAE presence with a negative $\delta^{13} \mathrm{C}$ excursion that coincides with the onset of KF-LIP along with elevated $\mathrm{Hg}$ and RSTM. Our data demonstrates a spatial $\mathrm{Hg}$ trend across the basin, where proximal settings are elevated in $\mathrm{Hg}$ and RSTM. Temporally, in proximal settings, post-T-OAE successions are $\mathrm{Hg}$-enriched throughout the Early-Middle Jurassic and possibly linked to NSD events. Alternatively, enhanced weathering might have played a role in bringing terrestrially-derived $\mathrm{Hg}$ into the marine environment. RSTM enrichment factors suggest a particulate shuttle mechanism acting beneath a perennial oxygen-minimum zone. Distal settings, however, have punctuated peaks of slightly elevated $\mathrm{Hg}$ after the T-OAE. Together, this work provides insights on the interplay between T-OAE, LIP, and Hg-RSTM systems during an important transition in the Earth's biogeochemical history.

Acknowledgements: This work has been financed by Gassco and Equinor. Gassco is the operator for the Norwegian gas transport system and of several gas processing and receiving terminals in Norway and in Europe. Equinor is an energy company with substantial international activities and the operator of a large part of Norwegian oil and gas production. 